Article

\title{
Optimization Study on Fluids for the Gravity-Driven Organic Power Cycle
}

\author{
Weixiu Shi ${ }^{1,2}$ and Lisheng Pan $^{3, *} *$ \\ 1 School of Environment and Energy Engineering, Beijing University of Civil Engineering and Architecture, \\ Beijing 100044, China; shiweixiu@bucea.edu.cn \\ 2 Beijing Engineering Research Center of Sustainable Energy and Buildings, Beijing University of Civil \\ Engineering and Architecture, Beijing 100044, China \\ 3 State Key Laboratory of High Temperature Gas Dynamics, Institute of Mechanics, Chinese Academy of \\ Sciences, Beijing 100190, China \\ * Correspondence: panlisheng@imech.ac.cn; Tel./Fax: +86-10-8254-4234
}

Received: 5 January 2019; Accepted: 21 February 2019; Published: 22 February 2019

check for updates

\begin{abstract}
The organic Rankine cycle (ORC) is efficient in using low-grade heat energy, while low pump efficiency and high pump leakage are usually serious problems. A gravity-driven organic power cycle (GDOPC) uses gravity instead of a pump to pressurize working fluid and has the potential to avoid problems associated with the pump. A theoretical method is used to study the performance and suitability of several fluids for GDOPC. The results show that the flow efficiency in high vertical pipes and the pump efficiency determine whether GDOPC gives better performance than ORC or not. When R245fa is selected as working fluid and evaporating temperature is $62{ }^{\circ} \mathrm{C}$, specific energy of GDOPC (flow efficiency is $80 \%$ ) is $2.5 \%$ higher than that of ORC (pump efficiency is $60 \%$ ). The improvement degree of specific energy and the liquid column height increase with increasing evaporating temperature. R1234yf and R227ea give good performance with specific energy of $4.84 \mathrm{~kJ} / \mathrm{kg}$ and $4.82 \mathrm{~kJ} / \mathrm{kg}$, respectively, while they need a liquid column as much as $76.55 \mathrm{~m}$ and $45.65 \mathrm{~m}$, respectively. Although R365mfc and cyclopentane do not give the most excellent cycle performance, they need liquid column height as low as $9.04 \mathrm{~m}$ and $10.88 \mathrm{~m}$, respectively. Fluid with low saturated pressure and high density may need low liquid column height and has the advantage to be used in practical applications.
\end{abstract}

Keywords: gravity driven organic power cycle (GDOPC); organic Rankine cycle (ORC); theoretical study; fluid optimization

\section{Introduction}

Nowadays, the energy crisis is becoming more and more serious. However, the reserve of low-grade heat energy is huge in nature and the society. It is helpful for alleviating an energy shortage and protecting the environment to use low-grade heat energy. A power cycle using unconventional working fluid has good application prospects in using low-grade heat energy [1,2].

A lot of investigation was carried out on optimization of working fluid and operating conditions for different heat sources. Shen et al. [3] developed an equation of state named crossover volume translation Soave-Redlich-Kwong to predict the thermodynamic properties of several hydrocarbons. Generally, the dry and isentropic fluids are most suitable for the organic Rankine cycle (ORC) [4]. Additionally, extensive research was executed to optimize working fluid for different heat sources [5-7]. Pan et al. [8] improved the theoretical analysis method of ORC based on radial flow turbine and gave the performance of several fluids for ORC using $90{ }^{\circ} \mathrm{C}$ hot water as a heat source. R227ea gave the largest net output power and the lowest thermal efficiency while R141b gave the least net output 
power and the highest thermal efficiency. The scroll expander, reciprocating expander, rotary vane expander, screw expander and rolling rotor expander are usually used in a small-scale ORC system, especially in an experimental system.

The expander is the key component of an ORC which impacts on the whole system performance. Many theoretical and experimental studies were executed by many researchers, with the aim of enhancing the expander efficiency or off-design performance. There are several expander types considered for ORC, such as the scroll expander, rotary vane expander, screw expander, piston expander, rolling rotor expander and turbine. Pantano et al. [9] compared the volumetric expander inlet forward radial micro turbine for an on-board ORC. Quoilin et al. [10] and Lemort et al. [11] studied the scroll expander for ORC by theoretical method and experimental method. A numerical model of an ORC system integrated with a scroll expander was proposed. Experimental data was used to validate the theoretical model. Internal leakages, supply pressure drop and mechanical losses are the main losses affecting performance of the scroll expander. Qiu et al. [12] also executed the investigation of a scroll expander driven by compressed air and its potential applications to ORC. Mascuch et al. [13] used a rotary vane expander on an experimental system of a kilowatt-scale biomass fired micro-CHP (Combined heat and power) unit based on ORC. Zhao et al. [14] developed a single screw expander for the ORC system and carried out an experimental study on the system's performance. The maximum shaft power of $3.27 \mathrm{~kW}$ was achieved. Wang et al. [15] established an ORC system driven by solar energy and executed experimental research with R245fa as working fluid. On the experimental system, a rolling rotor expander was fixed and gave the maximum isentropic efficiency of $45.2 \%$ and the maximum power of $1.73 \mathrm{~kW}$. Pan et al. [16] also tested a rolling rotor expander with $\mathrm{CO}_{2}$ as working fluid and obtained a maximum power generation of $1.7 \mathrm{~kW}$. Feng et al. [17] investigated influence of lubricant oil on expander performance on a $3 \mathrm{~kW}$ ORC experimental system. Generally speaking, radial flow turbine is more suitable for ORC than volume type expander or axial turbine in practical project. Radial flow turbine gives high efficiency for low volumetric flow rate and high pressure ratio [18]. Pei et al. [19] studied the performance of an ORC system integrated with a kW-scale radial flow turbine. A turbine isentropic efficiency of $65 \%$ and thermal efficiency of $6.8 \%$ were obtained in the experimental study with R123 as working fluid. Kang [20] designed and manufactured a two-stage radial turbine with the aim of improving cycle performance by increasing its pressure ratio. The maximum output power of $39.0 \mathrm{~kW}$ was achieved. A radial outflow turbine also attracted researchers' attention for an ORC power plant [21]. Pan et al. [22] used an experimental method to study regulation method in an ORC power generation experimental system and provided regularities in the relationships among turbine speed, load resistance and transmission-generator efficiency.

In addition, some novel cycles are also proposed for using low-grade heat energy. Miller et al. [23] and Srinivasan [24] et al. coupled an ORC with semiconductor power system and natural gas engine system, respectively, to improve the energy utilization ratio. Schenmaker et al. [25] proposed a new concept namely buoyancy ORC and analyzed performance with pentane and dichloromethane as working fluids. In the cycle, energy is obtained by utilizing the buoyancy force of the working fluid. For both working fluids, efficiency up to $26 \%$ was obtained with working temperatures below $100{ }^{\circ} \mathrm{C}$. A novel apparatus was proposed in a French patent [26], as shown in Figure 1. It provided electricity using gravity instead of a pump to drive the Rankine cycle. The inventor also pointed out that the weight of heavy organic working fluid enabled the pressurization and circulation. Li et al. [27] analyzed the novel cycle with organic working fluid and held the opinion that problems like low efficiency and leakage associated with the fluid pump can be avoided by omitting the pump in the novel cycle.

The novel gravity-driven organic Rankine cycle has good potential for using a low-grade heat source. This particle focuses on performance and working fluid for the cycle. The term of the gravity-driven organic power cycle (GDOPC) is used for the novel cycle with organic working fluid to distinguish it from a conventional ORC. A theoretical method is used to study the cycle performance of several fluids and search for the optimization principle for working fluid. 


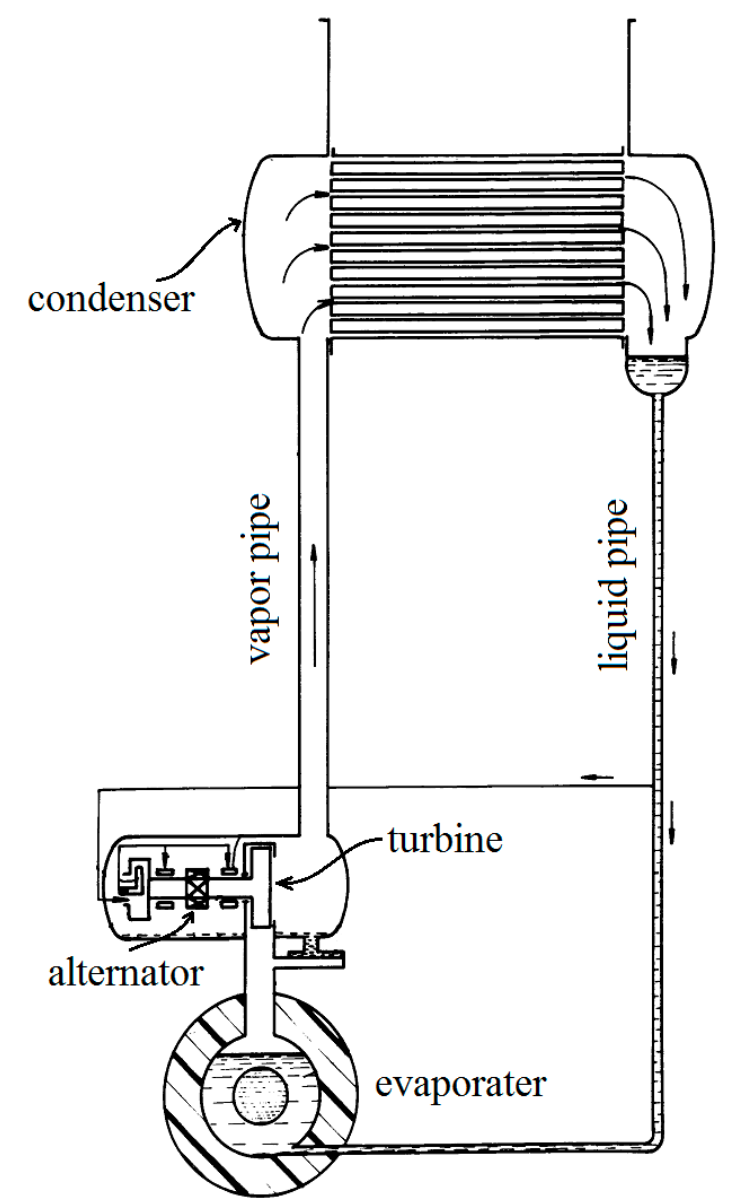

Figure 1. A novel apparatus in a French patent.

\section{Theoretical Method}

\subsection{Introduction of Gravity-Driven Organic Power Cycle (GDOPC)}

In a subcritical power cycle system, fluid is at either the liquid phase state or vapor phase state. Fluid density at the liquid phase state is much higher than that at the vapor phase state. Because of gravity, pressure at the liquid column bottom is much higher than that at the vapor column bottom. This pressure difference between liquid column bottom and vapor column bottom is used to drive fluid in a GDOPC. As shown in Figure 2, the process from state point 1 to state point 2 represents that vapor phase fluid with high temperature and high pressure expands in the turbine and outputs shaft power. The process from point 2 to point 3 is that fluid with low temperature and low pressure flows upwards along vertical vapor pipe (pressure at the top of the vapor column is slightly lower than that at the bottom). The process from state point 3 to state point 5 is that fluid is cooled and condensed by cooling water. For some dry fluids (with positive slope for saturated gas line), there is a large superheated degree at state point 3 , so a larger condenser is needed because of the low single-phase heat transfer coefficient. The dew point (point 4 ) appears somewhere in the condenser. Th process from state point 5 to state point 6 is that liquid fluid flows downwards and forms a high liquid column. Under the action of gravity, pressure at the bottom of the liquid column increases and then a higher pressure-under which evaporation happens later-is reached here. The evaporating process is represented by process from state point 6 to state point 1 . The bubble point and dew point appear somewhere in the evaporator. 


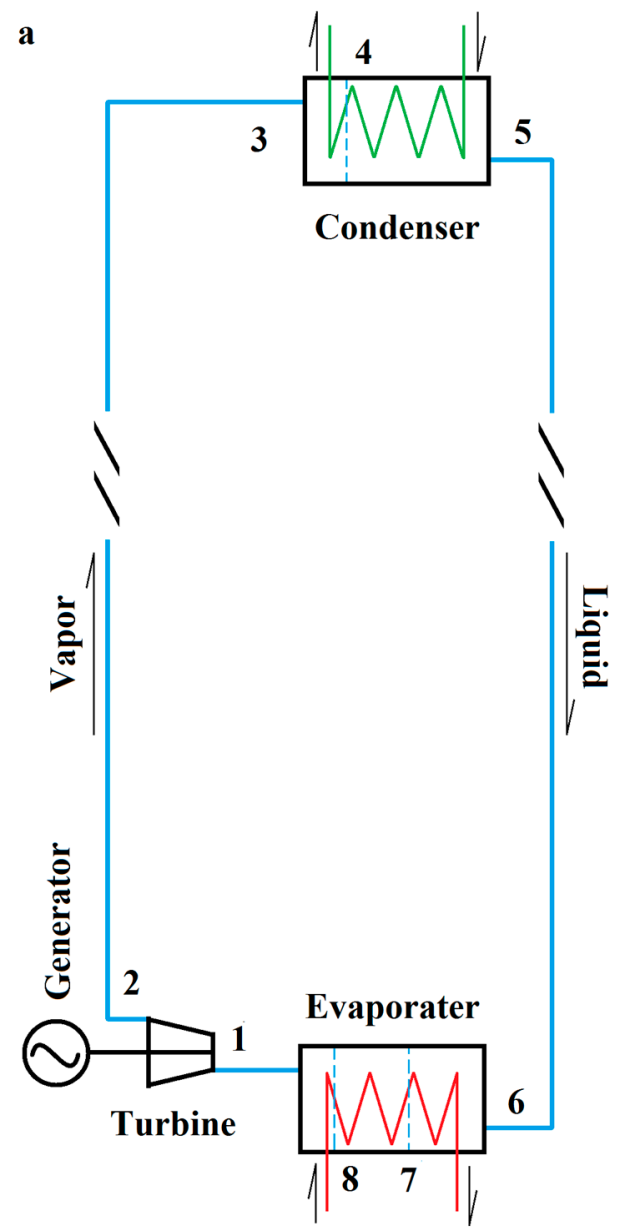

(a)

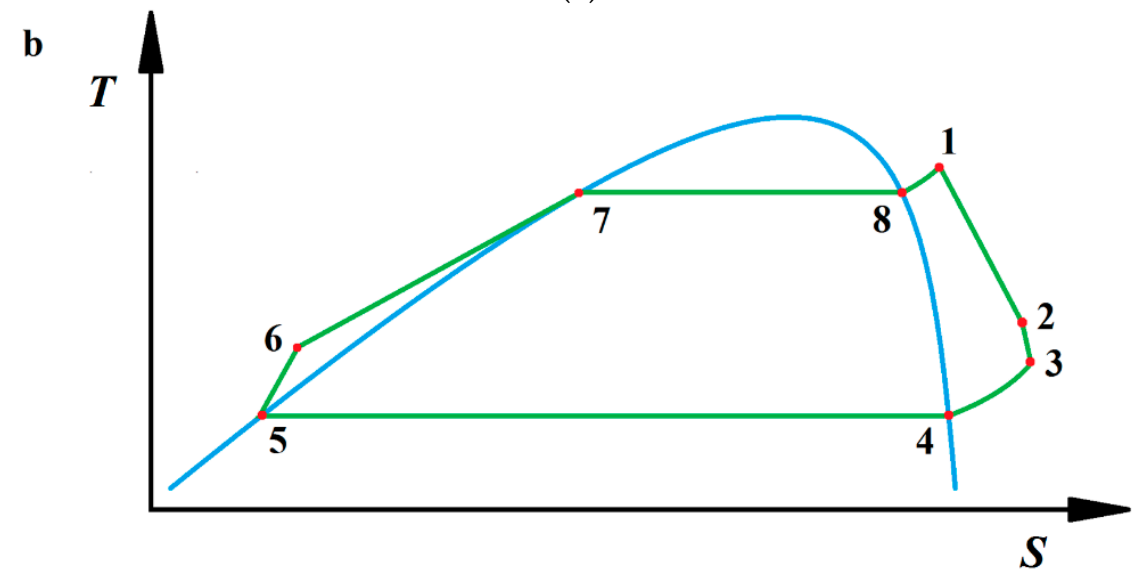

(b)

Figure 2. Sketch maps for GDOPC. (a) Flow chart system; (b) Cycle process.

In this article, the turbine is located at the bottom of the system as shown in Figure 2. However, it also can be located at the top of the system [28]. If the turbine is located at the top, the positions of the process from point 2 to point 3 and the process from point 1 to point 2 as shown in Figure $2 b$ should be exchanged. Usually, a GDOPC system needs a very high liquid column which is determined by heat source parameters and working fluid. Because of the large height from the geothermal heat source to the ground, the GDOPC may have the potential to use geothermal energy. 


\subsection{Considered Fluids}

Fluid containing chlorine is harmful for ozone, so only HFCs, HFOs, CFs and HCs are selected as working fluid. The ODP of all considered fluids is 0 . The basic thermal properties and environmental properties of considered fluids are shown in Table 1 [29]. Also, these fluids are classified by a new ACZMN sequence method [30] with $20^{\circ} \mathrm{C}$ as lowermost temperature. In the method, each letter of the term ACZMN stands for one point on the saturated curve of the fluid.

Table 1. The basic thermal properties and environmental properties of considered fluids.

\begin{tabular}{cccccccc}
\hline Substance & $\begin{array}{c}\boldsymbol{M} \\
\mathbf{g} / \mathbf{m o l}\end{array}$ & $\begin{array}{c}\boldsymbol{t}_{\mathbf{b}} \\
{ }^{\circ} \mathbf{C}\end{array}$ & $\begin{array}{c}\boldsymbol{t}_{\mathbf{c}} \\
{ }^{\circ} \mathbf{C}\end{array}$ & $\begin{array}{c}\boldsymbol{p}_{\mathbf{c}} \\
\mathbf{M P a}\end{array}$ & $\begin{array}{c}\text { Atmospheric Life } \\
\text { year }\end{array}$ & $\begin{array}{c}\text { GWP } \\
\text { 100 year }\end{array}$ & Category \\
\hline R1234yf & 114.04 & -29.45 & 94.7 & 3.382 & 0.03 & 4 & ACZM \\
R1234ze & 114.04 & -18.95 & 109.37 & 3.636 & - & - & ACZM \\
R134a & 102.03 & -26.07 & 101.06 & 4.059 & 14 & 1430 & ACZ \\
R227ea & 170.03 & -16.34 & 101.75 & 2.925 & 42 & 3220 & ACZM \\
R236ea & 152.04 & 6.19 & 139.29 & 3.502 & 8 & 710 & ACZM \\
R236fa & 152.04 & -1.44 & 124.92 & 3.2 & 240 & 9810 & ACZM \\
R245ca & 134.05 & 25.13 & 174.42 & 3.925 & 6.2 & 693 & AZCM \\
R245fa & 134.05 & 15.14 & 154.01 & 3.651 & 7.6 & 1030 & ACZM \\
RC318 & 200.03 & -6.0 & 115.20 & 2.78 & 3200 & 10250 & AZCM \\
R365mfc & 148.07 & 40.15 & 186.85 & 3.266 & - & - & AZCM \\
R600 & 58.12 & -0.49 & 151.98 & 3.796 & 0.02 & $\sim 20$ & ACZM \\
R600a & 58.12 & -11.75 & 134.66 & 3.629 & 0.02 & $\sim 20$ & ACZM \\
trans-butene & 56.11 & 0.88 & 155.46 & 4.027 & $\sim 0$ & $\sim 20$ & ACNZM \\
cis-butene & 56.11 & 3.72 & 162.6 & 4.226 & $\sim 0$ & $\sim 20$ & ACNZM \\
cyclopentane & 70.13 & 49.25 & 238.54 & 4.515 & 0.01 & $\sim 20$ & ANZCM \\
\hline
\end{tabular}

\subsection{Analysis Method of GDOPC}

Figure 3a is a whole block diagram of the theoretical analysis method for GDOPC. For general fluids, a very high liquid column (high system) is usually needed to prove the cycle pressure difference between evaporating pressure and condensing pressure. Although vapor has much less density than liquid, the pressure drop of the vapor column from the bottom (state point 2) to the top (state point 3) cannot be ignored. Additionally, the kinetic energy loss exists along the vapor column and the liquid column. The pressure drop of the vapor column and the kinetic energy loss are all taken into account in the theoretical method. The computation methods about the liquid column and the vapor column are shown in Figure $3 b, c$, respectively. Therefore, processes in a vertical vapor pipe and vertical liquid pipe are non-isentropic, which can be seen from Figure $2 b$. 


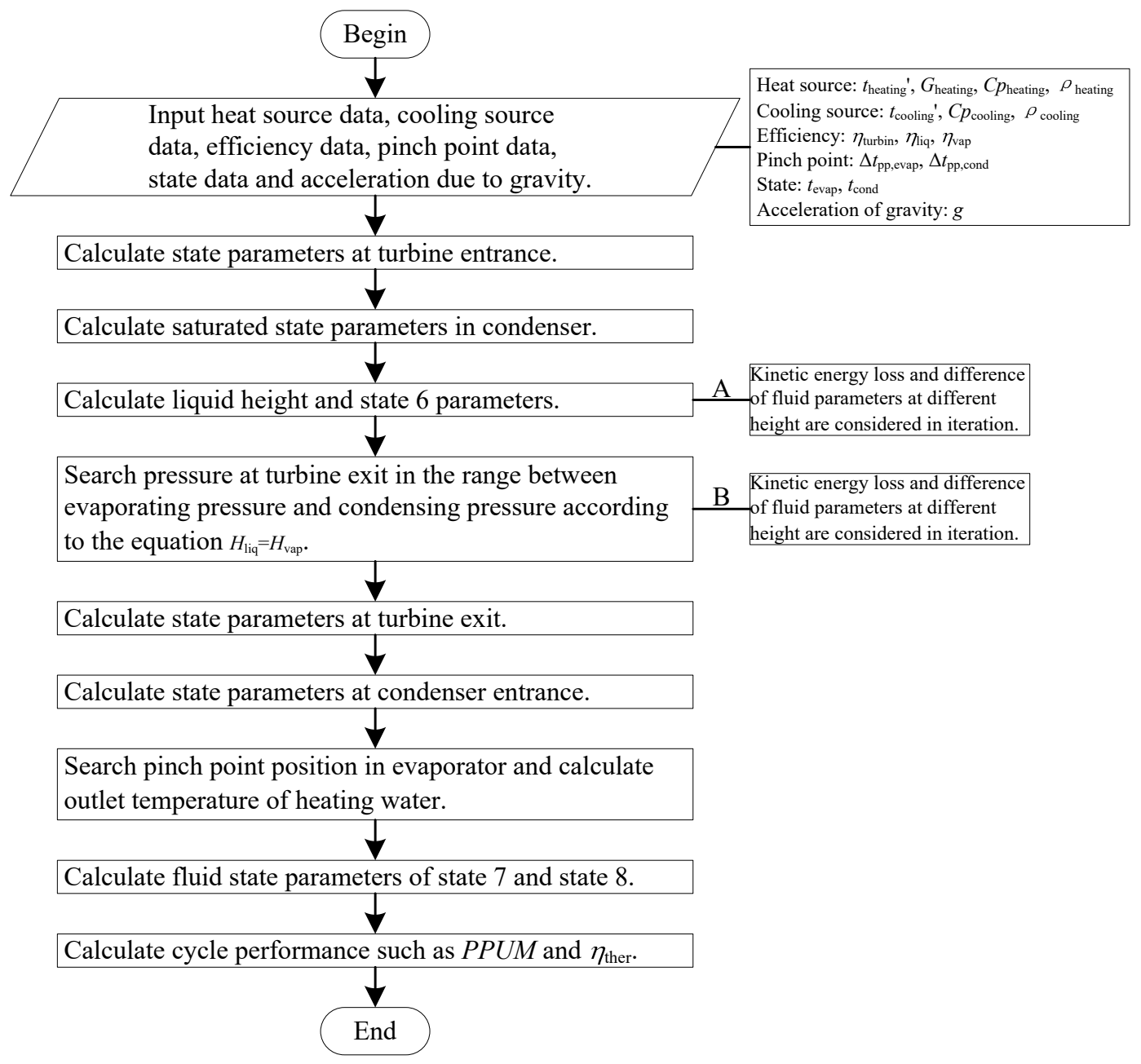

(a)

Figure 3. Cont. 


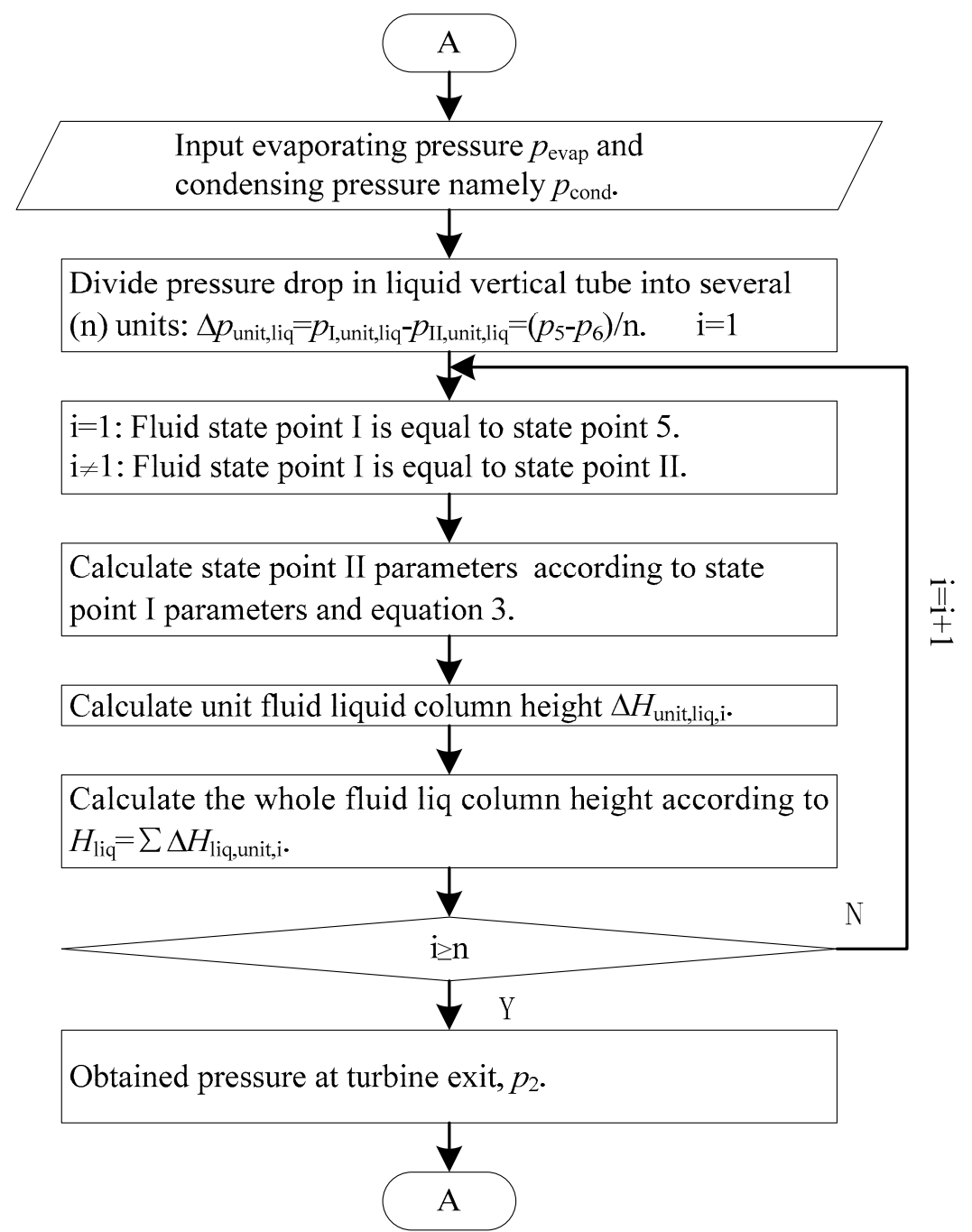

(b)

Figure 3. Cont. 


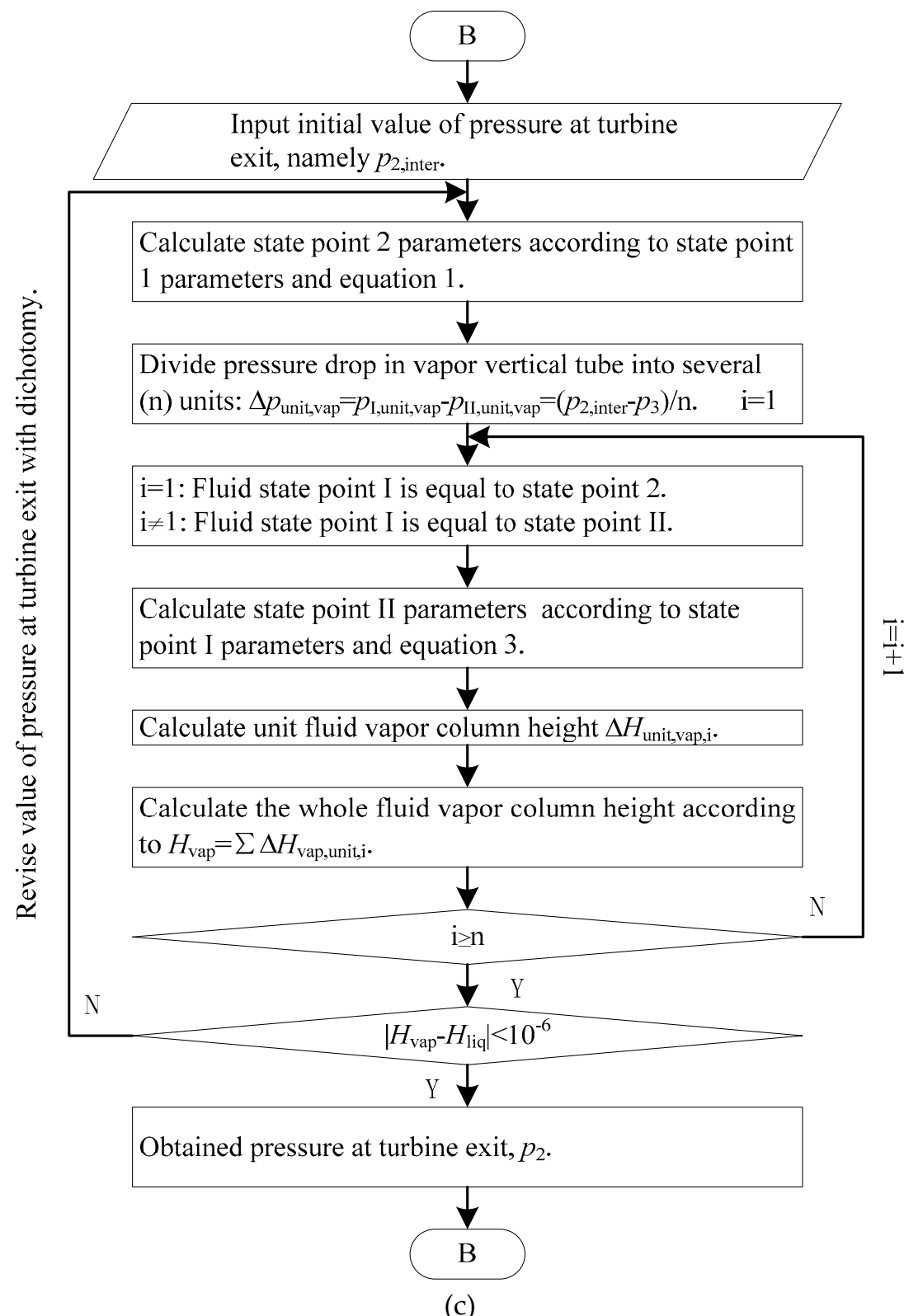

Figure 3. Block diagram for the theoretical analysis method for GDOPC. (a) Whole block diagram; (b) Details for process 5 to 6; (c) Details for process 2 to 3.

In this article, REFPROP 9.0 [31] is used to obtain fluid thermal properties. For example, when a few state properties are provided, such as temperature and pressure for single phase, REFPROP 9.0 can output other thermal properties, such as enthalpy, entropy, density and specific heat. In the theoretical analysis method, the turbine efficiency is designated. Fluid state parameters at the turbine exit can be computed using turbine efficiency and fluid state parameters at the turbine entrance according to Equation (1). Fluid parameters like temperature and density change along the pipe, so the process from state point 5 to state point 6 is divided into several units. The liquid fluid flow efficiency is defined as Equation (2) in order to take account of the kinetic energy loss along the liquid vertical pipe. The fluid liquid column height of each unit as well as the whole process in the vertical pipe can be expressed as Equation (3). The pressure difference between evaporating pressure and condensing 
pressure is completely provided by the fluid liquid column. The detailed computation method is shown in Figure 3b.

$$
\begin{gathered}
\eta_{\text {tur, isen }}=\frac{h_{1}-h_{2}}{h_{1}-h_{2, \text { isen }}} \\
\eta_{\text {liq }}=\frac{h_{\mathrm{II}, \text { isen,liq,unit,i }}-h_{\mathrm{I}, \mathrm{liq}, \mathrm{unit}, \mathrm{i}}}{h_{\mathrm{II}, \mathrm{liq}, \mathrm{unit}, \mathrm{i}}-h_{\mathrm{I}, \mathrm{liq}, \mathrm{unit}, \mathrm{i}}} \\
\Delta H_{\text {liq,unit,i }}=\frac{p_{\mathrm{II}, \mathrm{liq}, \mathrm{unit}, \mathrm{i}}-p_{\mathrm{I}, \mathrm{liq}, \mathrm{uni}, \mathrm{i}}}{\bar{\rho}_{\text {liq, } \mathrm{uni}, \mathrm{i}} \mathrm{g}} \quad H_{\text {liq }}=\sum_{i=1}^{n} \Delta H_{\text {liq,unit,i }}
\end{gathered}
$$

The process from state point 2 to state point 3 is also divided into several units and the vapor fluid flow efficiency is defined as Equation (4). The vapor column height in each unit as well as the whole vertical pipe can be expressed as Equation (5). The pressure values of state point 1 and state point 3 can be easily obtained by computing the saturated pressure at evaporating temperature and condensing temperature. However, when the pressure difference of the vapor column and the kinetic energy losses are all taken into account, state point 2 parameters must be obtained by iterative method which is detailedly shown in Figure 3c.

$$
\begin{aligned}
& \eta_{\text {vap }}=\frac{h_{\mathrm{I}, \text { vap }, \text { unit, } \mathrm{i}}-h_{\mathrm{II}, \mathrm{vap}, \text { unit,i }}}{h_{\mathrm{I}, \mathrm{vap}, \text { unit,i }}-h_{\mathrm{II}, \text { isen,vap, unit,i }}} \\
& \Delta H_{\text {vap }, \text { unit, } \mathrm{i}}=\frac{p_{\mathrm{I}, \text { vap }, \text { unit, } \mathrm{i}}-p_{\mathrm{II}, \text { vap }, \text { unit, } \mathrm{i}}}{\bar{\rho}_{\mathrm{vap}, \text { unit }, \mathrm{i}} g} \quad H_{\mathrm{vap}}=\sum_{i=1}^{n} \Delta H_{\text {vap }, \text { unit }, \mathrm{i}}
\end{aligned}
$$

The heat capacity in the evaporator can be expressed as Equation (6). Power is not inputted into the GDOPC system, so the net output power is the same as the turbine output power. Therefore, the thermal efficiency can be expressed as Equation (7a). The ORC system is usually integrated with a fluid pump which consumes power, so its thermal efficiency is expressed as Equation (7b).

$$
\begin{gathered}
\dot{Q}_{\text {evap }}=\dot{m}_{\text {fluid }}\left(h_{1}-h_{6}\right) \\
\eta_{\text {ther }}=\frac{\dot{P}_{\text {tur }}}{\dot{Q}_{\text {evap }}} \\
\eta_{\text {ther }}=\frac{\dot{P}_{\text {tur }}-\dot{P}_{\text {pump }}}{\dot{Q}_{\text {evap }}}
\end{gathered}
$$

Power output per unit mass flow rate of the heat source fluid can represent the benefits from the heat source and is usually selected as the objective function. In this article, the specific energy ( $E_{\text {specific }}$ ) is defined as Equation (8a) for GDOPC while it is defined as Equation (8b) for conventional ORC. The unit of specific energy is $\mathrm{kJ} / \mathrm{kg}$. The higher the specific energy, the more the benefit can be obtained from the heat source.

$$
\begin{gathered}
E_{\text {specific }}=\frac{\dot{P}_{\text {tur }}}{\dot{m}_{\text {hot water }}} \\
E_{\text {specific }}=\frac{\dot{P}_{\text {tur }}-\dot{P}_{\text {pump }}}{\dot{m}_{\text {hot water }}}
\end{gathered}
$$

\section{Results and Discussion}

\subsection{Comparison between GDOPC and Organic Rankine Cycle (ORC)}

The significant advantage of GDOPC is that the fluid pump is omitted in the system. Although a pump consumes much lower power than turbine outputs, the seal problem of the pump is solved 
and pressurizing efficiency can be increased slightly. These improvements can increase the thermal efficiency and decrease the system's cost. The flow efficiency along high vertical pipes determines the thermal efficiency and the vertical pipes' impacts on the system cost. In addition, the new system is a little more complicated than ORC system, because of the high vertical pipes. The pressurizing process can be self-adapting. In other words, the liquid column height varies with the difference between evaporating pressure to condensing pressure if the vertical pipes are high enough.

In this section, a comparative study between GDOPC and ORC is carried out using R245fa as working fluid in both cycles. Specified conditions are shown in Table 2.

Table 2. Specified conditions in the comparative analysis.

\begin{tabular}{ccc}
\hline Items & Unit & Values \\
\hline Hot water inlet temperature & ${ }^{\circ} \mathrm{C}$ & 90 \\
Cooling water inlet temperature & ${ }^{\circ} \mathrm{C}$ & 30 \\
Turbine efficiency & $\%$ & 65 \\
Pump efficiency for organic Rankine cycle (ORC) & $\%$ & $60-80$ \\
Liquid flow efficiency & $\%$ & 80 \\
Vapor flow efficiency & $\%$ & 80 \\
Evaporating temperature & ${ }^{\circ} \mathrm{C}$ & $50-84$ \\
Condensing temperature & ${ }^{\circ} \mathrm{C}$ & 40 \\
Superheat degree & ${ }^{\circ} \mathrm{C}$ & 0 \\
Pinch point temperature difference & ${ }^{\circ} \mathrm{C}$ & 5 \\
Acceleration of gravity & $\mathrm{m} / \mathrm{s}^{2}$ & 9.8 \\
\hline
\end{tabular}

As shown in Figure 4, for both cycles, there is a maximum specific energy appearing in the condition with evaporating temperature of about $62{ }^{\circ} \mathrm{C}$. For ORC, specific energy increases with pump efficiency, especially near the optimal condition. In considered conditions, the specific energy of GDOPC is a little higher than that of ORC. The average absorbing heat temperature in the evaporator increases with the increase of evaporating temperature. Consequently, the cycle thermal efficiency increases with increasing evaporating temperature, which is helpful for enhancing specific energy. The hot water outlet temperature increases with the increase of evaporating temperature. Accordingly, heat capacity in the evaporator decreases with increasing evaporating temperature, which is harmful for increasing specific energy. Therefore, the maximum specific energy appears under the influence of the two factors. In the conventional ORC system, a pump is used to pressurize and transport the fluid. The net power of the system is lower than the turbine output power because of electric power consumed by the fluid pump. The net power of GDOPC is equal to the turbine output power because input power is not consumed by other instruments. But there is kinetic energy loss along the high vertical pipes, which decreases the turbine output power. The essence of GDOPC is pressurizing fluid directly by heat energy. 


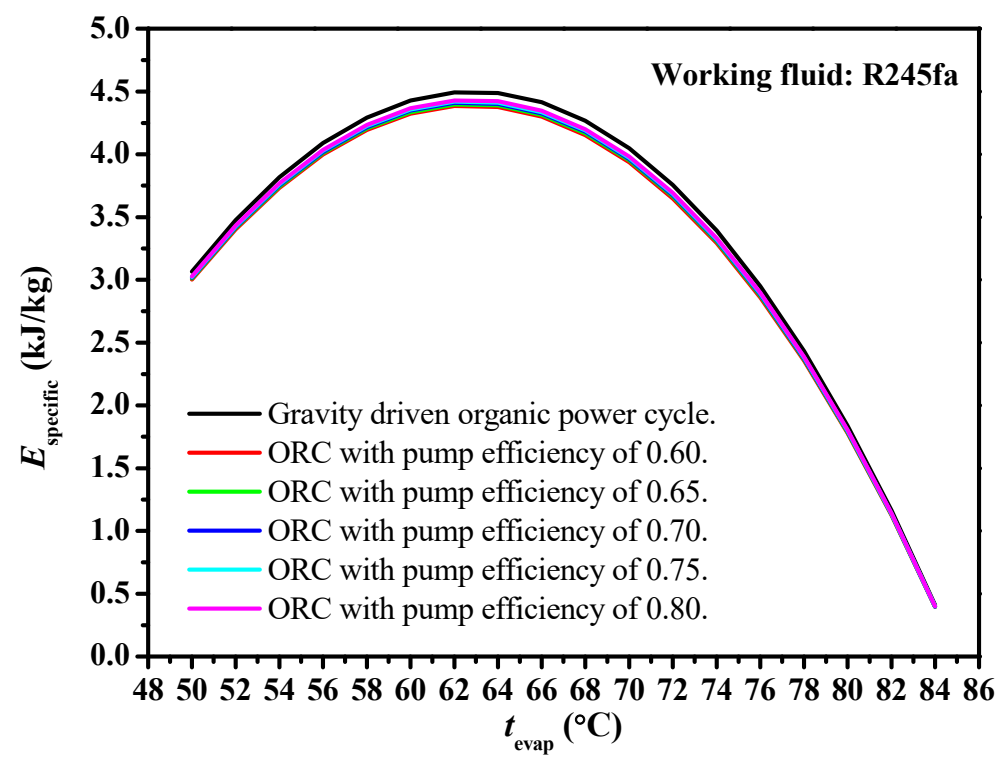

Figure 4. The specific energy comparison between GDOPC and ORC.

As shown in Figure 5, it is obviously that the specific energy is improved by using GDOPC in considered conditions. The lower the pump efficiency in the ORC, the higher the improvement degree. The advantage becomes more and more obvious with increasing evaporating temperature. At the optimal condition with evaporating temperature of $62{ }^{\circ} \mathrm{C}$, the improvement degree is $2.5 \%$ with the pump efficiency of $60 \%$ in the ORC. In a practical application, the pump efficiency is usually about $60 \%$. An appropriate efficiency of $80 \%$ is used for the flow efficiency in the high vertical pipes.

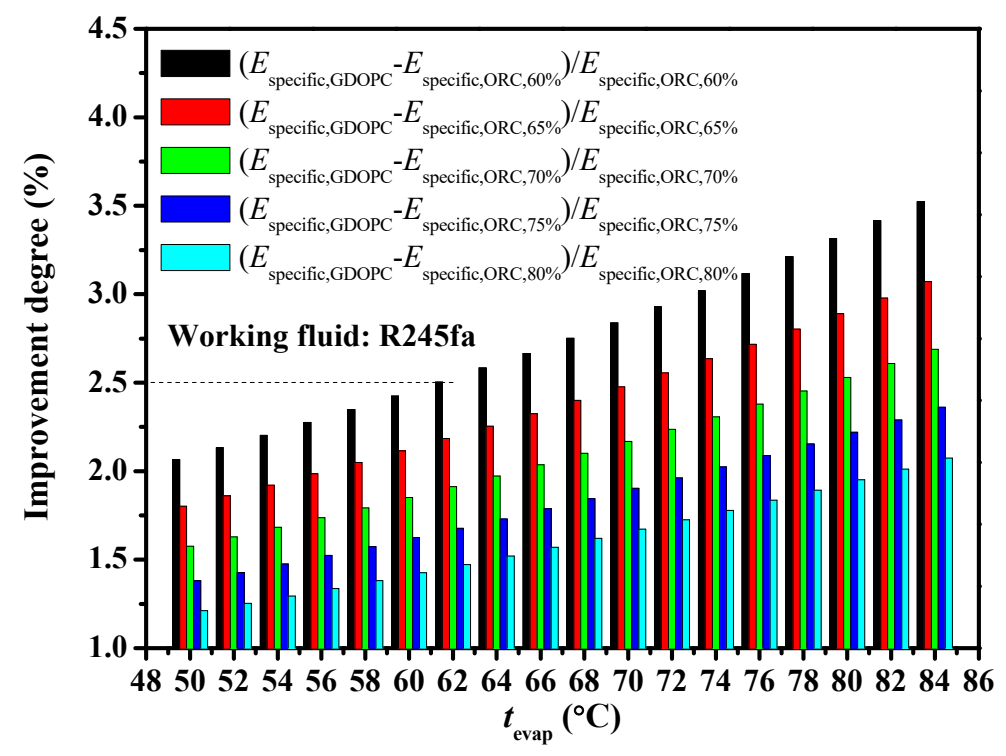

Figure 5. The improvement degree of specific energy.

In considered conditions, the higher the evaporating temperature, the higher the improvement degree. However, a higher fluid liquid column is needed in the conditions with higher evaporating temperature, as shown in Figure 6. For example, in the condition with heat source temperature of $150{ }^{\circ} \mathrm{C}$, evaporating temperature of $130^{\circ} \mathrm{C}$ and working fluid of $\mathrm{R} 245 \mathrm{fa}$, the improvement degree of specific energy and cycle thermal efficiency can reach $7.1 \%$ and $6.8 \%$ while the fluid liquid column reaches $164.6 \mathrm{~m}$. That means the system must be higher under higher evaporating temperature. Then, the construction difficulty and the system cost increase with increasing the system height. 


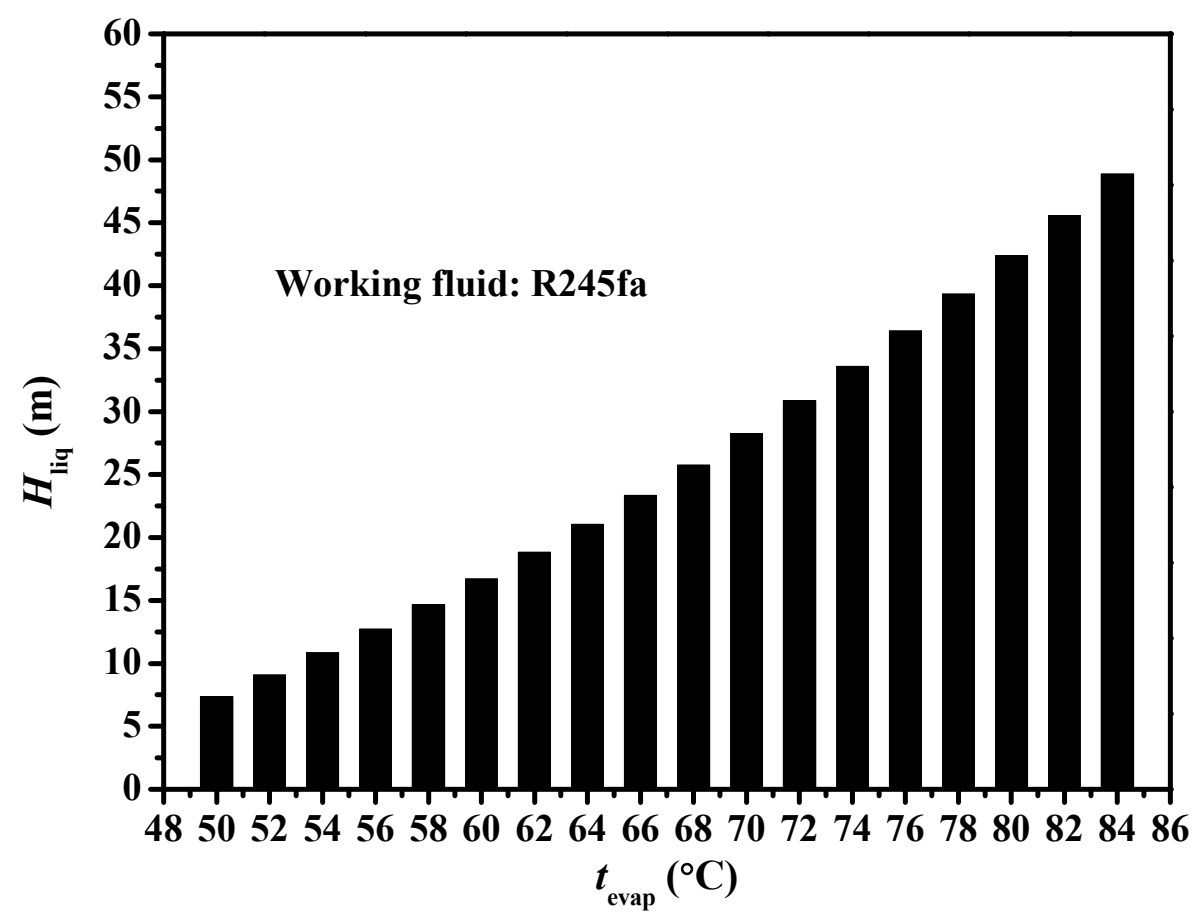

Figure 6. Variation of the fluid liquid column height with evaporating temperature.

\subsection{Analysis on Pressure Drop and Heat Transfer of GDOPC}

There are two important factors that impact the performance of GDOPC, namely, heat transfer in heat exchangers and resistance pressure drop in the system. Total pressure difference in the system is produced by the fluid liquid column and is proportional to its height. In the cycle, the total pressure difference is consumed by turbine and flow resistance in the system. The local resistance in the system can be expressed as $\varsigma\left(\rho u^{2} / 2\right)$ and the on-way resistance can be expressed as $(\lambda l / d) \cdot\left(\rho u^{2} / 2\right)$. The on-way resistance coefficient $\lambda$ is determined by the pipe roughness and the Reynolds number according to the flow pattern. Therefore, the local resistance is proportional to $u^{2}$ while the on-way resistance is not in some flow patterns. The rough turbulence zone is selected in this analysis because the on-way resistance coefficient $\lambda$ is only determined by the pipe roughness in this flow pattern. Then in the analysis, not only the local resistance, but also the on-way resistance, are proportional to $u^{2}$. Hence the total pressure difference can be expressed as,

$$
\Delta p_{\text {total }}=\Delta p_{\text {tur }}+\xi \frac{\rho u^{2}}{2}
$$

There are three heat transfer types in the heat exchangers in the system, such as single phase heat transfer, boiling heat transfer and condensation heat transfer. Many factors, namely, mass flow rate, flow area, flow pattern, heat flux density and temperature difference impact on the boiling heat transfer and the condensation heat transfer. Single phase heat transfer, by contrast, is simpler, as shown in Equation (10), if the shell and tube heat exchanger is selected and the working fluid flows in the tube pass. The coefficient $n$ is specified as 0.4 when the fluid is heated and is specified as 0.3 when the fluid is cooled. From Equation (10), it can be concluded that the heat transfer coefficient is proportional to $u^{0.8}$. The higher the velocity, the higher the heat transfer coefficient is. In this analysis, single phase heat transfer is selected to study the variation of heat transfer coefficient.

$$
N u=0.023 R e^{0.8} \operatorname{Pr}^{n}
$$

For R245fa, the optimal condition with evaporating temperature of $62{ }^{\circ} \mathrm{C}$ is selected as the standard condition to analyze the pressure drop and the heat transfer. In the standard condition, the 
turbine pressure drop is $0.2366 \mathrm{MPa}$ and the resistance pressure drop is $0.0025 \mathrm{MPa}$. The resistance pressure drop is as much as $1.05 \%$ of the total pressure difference. Figure 7 shows the variations of cycle performance, namely, fluid velocity and heat transfer coefficient with the increase of resistance pressure drop. As shown in the figure, velocity in the pipes increases with the increase of resistance pressure drop, as well as the heat transfer coefficient. The resistance pressure drop is proportional to $u^{2}$, which is stated above. Therefore, the velocity increases with increasing the resistance pressure drop ratio. From the above analysis about heat transfer, heat transfer coefficient is proportional to $u^{0.8}$. Therefore, the heat transfer coefficient also increases with increasing resistance pressure drop ratio.

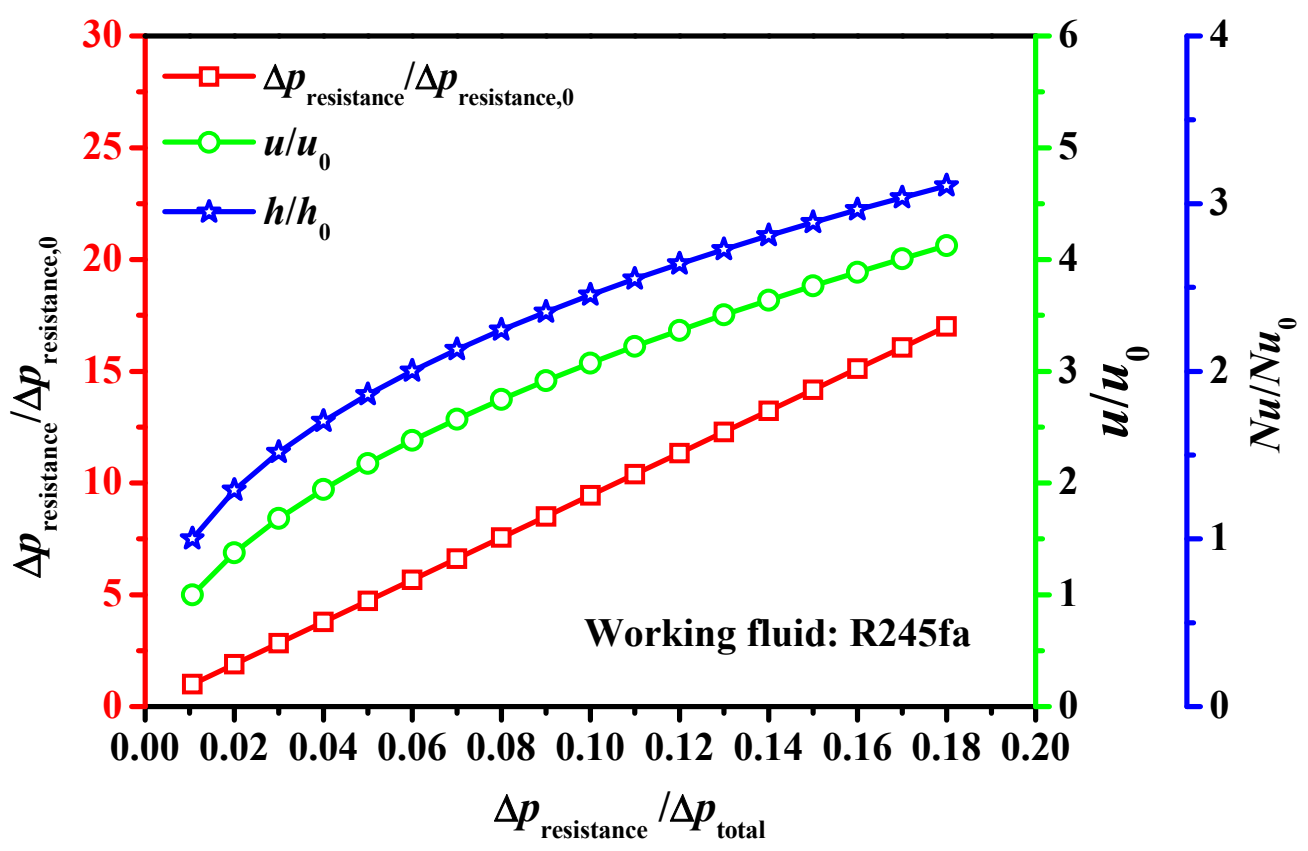

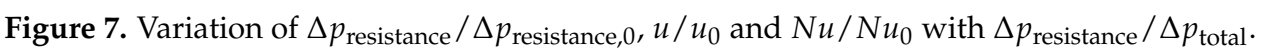

\subsection{The Performance of Several Organic Fluids for GDOPC}

The performance of 15 organic fluids for GDOPC is investigated in this section. The specified conditions are the same as in Section 3.1, as shown in Table 2. As shown in Figure 8, each fluid gives different specific energy from each other, especially in the range from $60{ }^{\circ} \mathrm{C}$ to $66^{\circ} \mathrm{C}$, where each fluid has a maximum specific energy. In considered conditions, R1234yf and R227ea give higher specific energy than the other fluids while cyclopentane gives the lowest specific energy. 


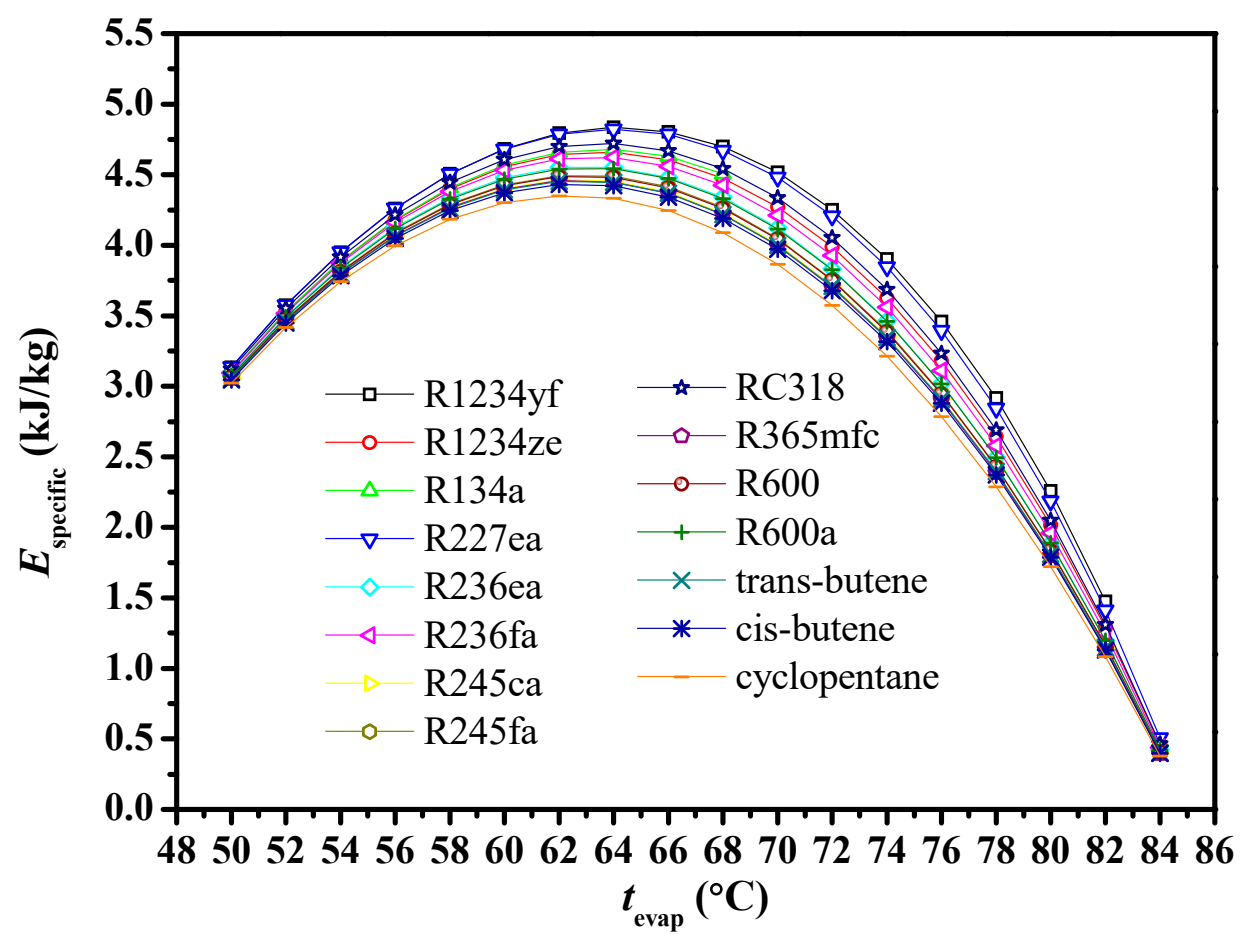

Figure 8. Variation of specific energy with evaporating temperature.

Specific energy is determined by cycle thermal efficiency and hot water outlet temperature, which is explained in Section 3.1. In considered conditions, deviations for different fluids exist for not only cycle thermal efficiency but also hot water outlet temperature. Deviation of hot water outlet temperature tends to zero with increasing evaporating temperature, as shown in Figure 9, while deviation of cycle thermal efficiency tends to zero with decreasing evaporating temperature, which is indicated in Figure 10. Therefore, the maximum deviations of specific energy for different fluids appear in considered conditions. The deviation tends to zero with increasing or decreasing evaporating temperature.

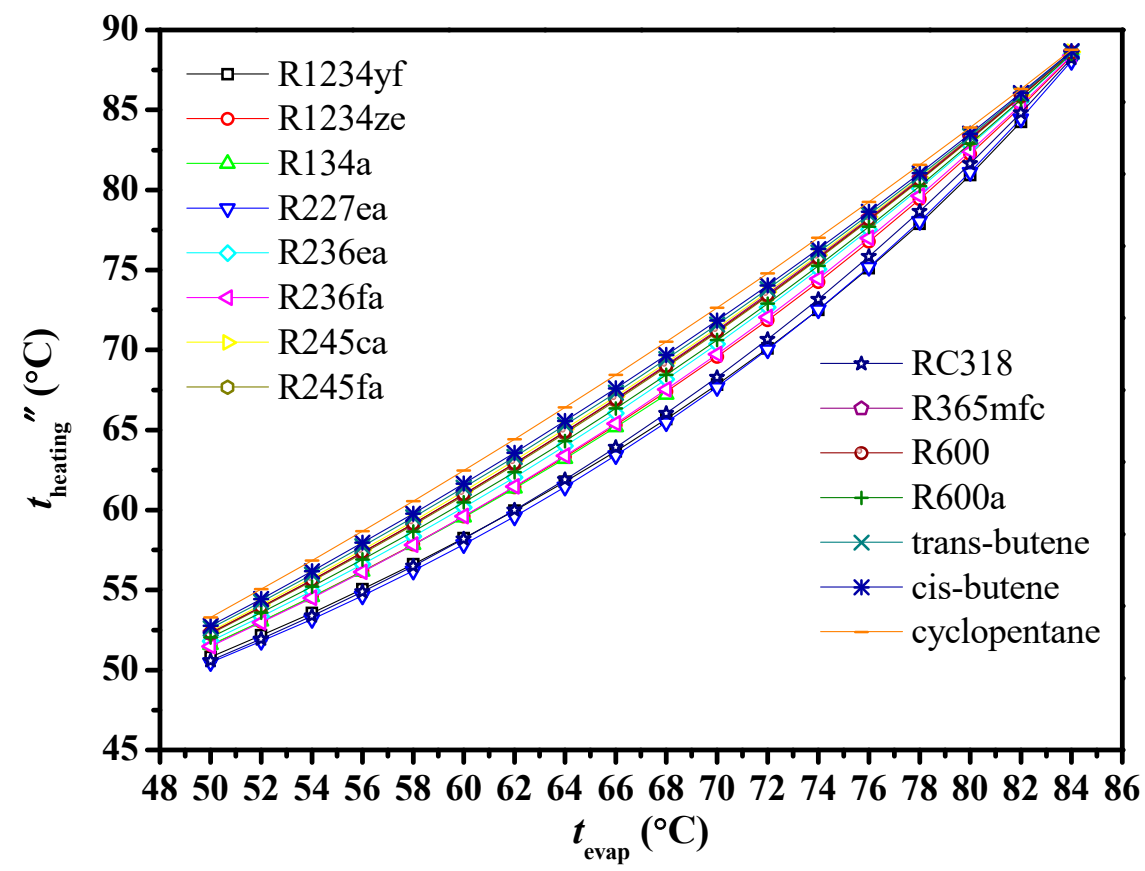

Figure 9. Variation of hot water outlet temperature with evaporating temperature. 
As shown in Figure 10, for each considered fluid, cycle thermal efficiency increases with increasing evaporating temperature. In considered conditions, cyclopentane gives the highest cycle thermal efficiency while R227ea and RC318 give lower cycle thermal efficiency. Cycle thermal efficiency depends on average absorbing heat temperature in the evaporator and average releasing heat temperature in the condenser. Cycle thermal efficiency increases with increasing absorbing heat temperature, as well as decreasing releasing heat temperature. In the considered conditions, average absorbing temperature increases with increasing evaporating temperature while average releasing temperature keeps constant in general. Therefore, thermal efficiency increases with the increase of evaporating temperature, which is similar to that of ORC.

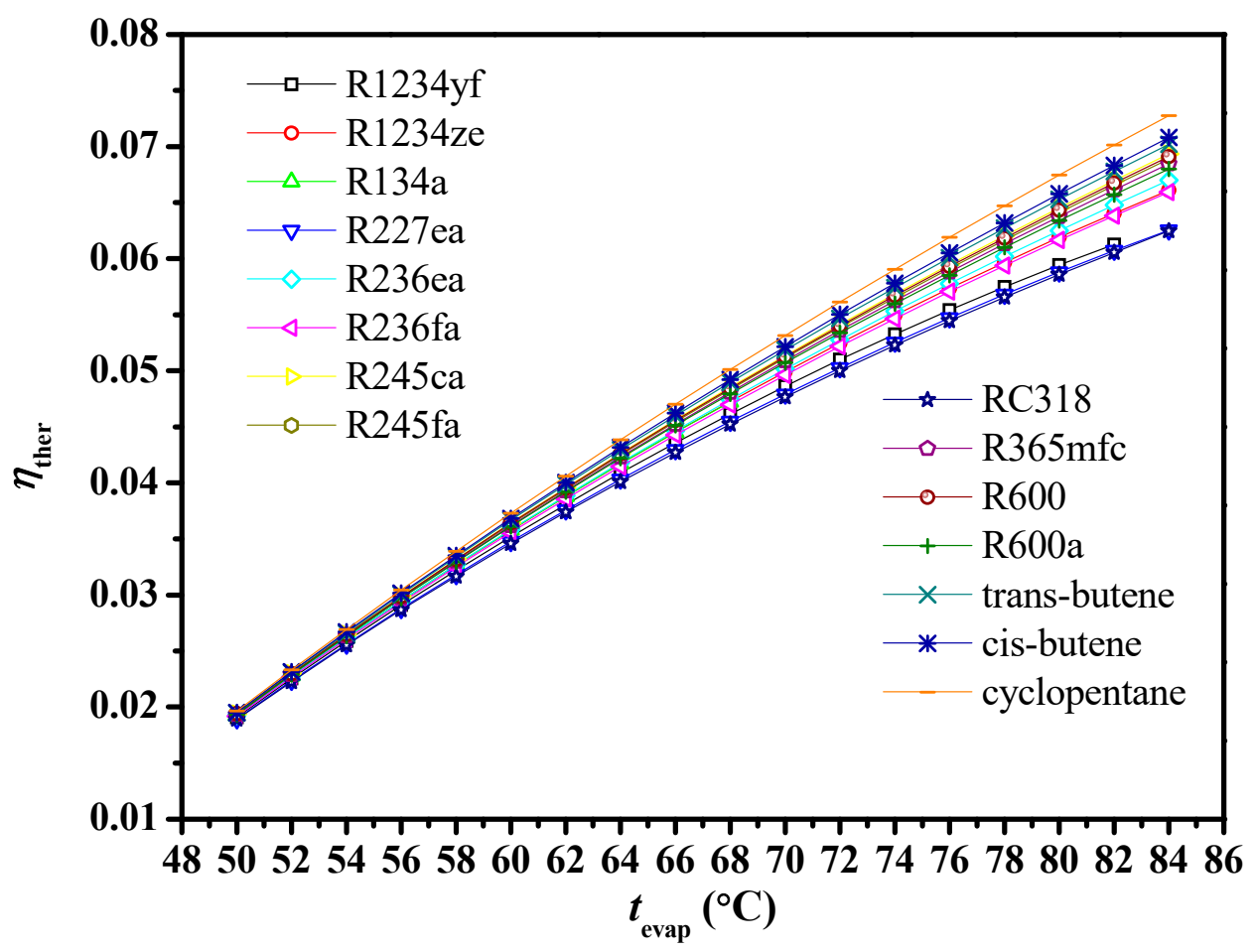

Figure 10. Variation of thermal efficiency with evaporating temperature.

The optimal condition for each fluid is defined as the condition in which specific energy appears. Figure 11 shows specific energy, cycle thermal efficiency and liquid column height in the optimal condition for each fluid. Among considered fluids, R1234yf and R227ea give higher specific energy than the others and the values are $4.84 \mathrm{~kJ} / \mathrm{kg}$ and $4.82 \mathrm{~kJ} / \mathrm{kg}$, respectively. Their cycle thermal efficiencies are $4.09 \%$ and $4.03 \%$, respectively. However, they need high fluid liquid columns and the values are $76.55 \mathrm{~m}$ and $45.65 \mathrm{~m}$, respectively. Although R1234yf and R227ea have good performance for GDOPC, the disadvantage of high construction difficulty and system cost limits the use of the two fluids. R365mfc and cyclopentane do not have excellent specific energy and cycle thermal efficiency, but they give very low liquid column height. In the optimal condition, R365mfc gives a specific energy of $4.46 \mathrm{~kJ} / \mathrm{kg}$ and a cycle thermal efficiency of $3.93 \%$. Its liquid column height is as low as $9.04 \mathrm{~m}$. For cyclopentane, a liquid column height of $10.88 \mathrm{~m}$ is needed while the corresponding specific energy and cycle thermal efficiency are $4.35 \mathrm{~kJ} / \mathrm{kg}$ and $4.06 \%$, respectively. Therefore, they have potential to be used with high evaporating temperature for GDOPC. 


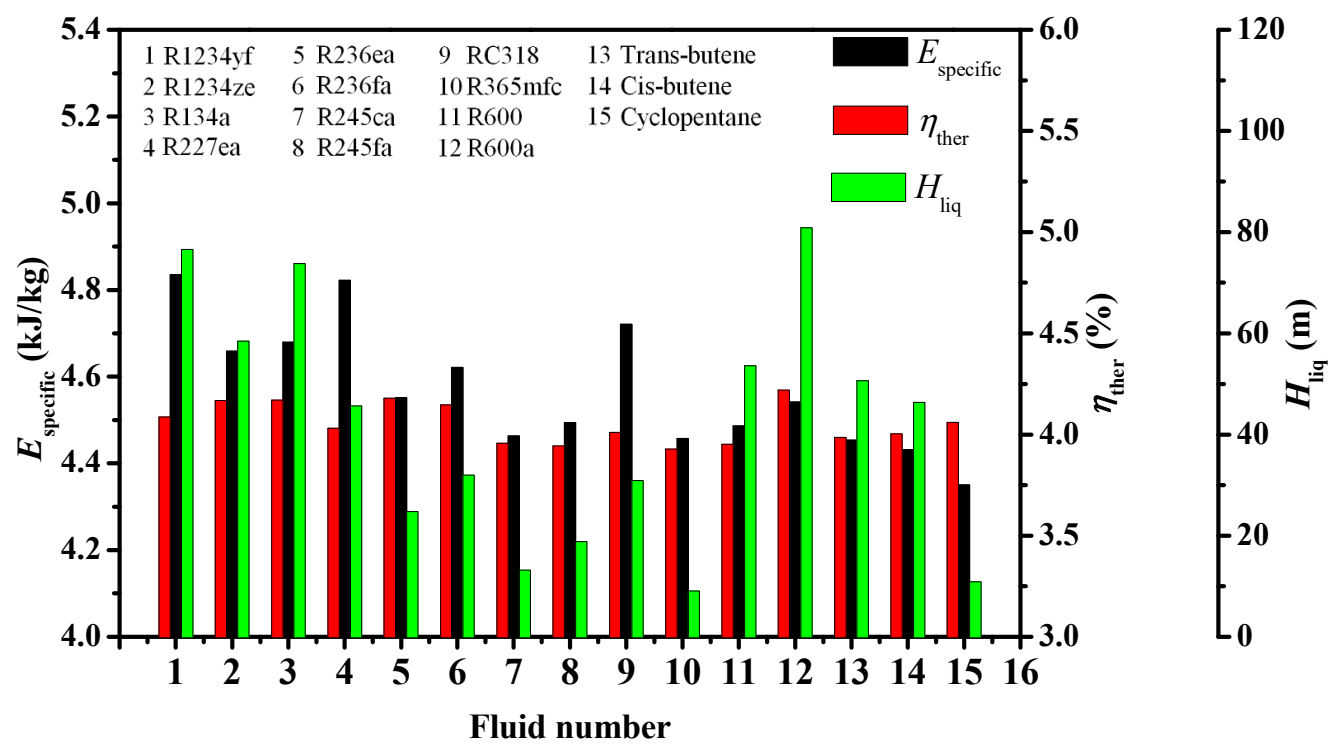

Figure 11. Performance comparison in each optimal condition.

Figure 12 shows three parameters, namely, difference between evaporating pressure (saturated pressure at $62{ }^{\circ} \mathrm{C}$ ) and condensing pressure (saturated pressure at $40{ }^{\circ} \mathrm{C}$ ), saturated liquid density at condensing temperature $\left(40^{\circ} \mathrm{C}\right)$, and liquid column height with evaporating temperature of $62{ }^{\circ} \mathrm{C}$. The liquid column height is correlated with pressure difference and saturated liquid density at the condensing temperature. For fluids from number 1 to number 10, the saturated liquid density are similar, so the difference of liquid column height is caused generally by the pressure difference. The spider diagrams of pressure difference and liquid column height are similar for fluids from number 1 to number 10. For fluids from number 11 to number 15, the saturated liquid densities are very different from each other and the spider diagram shape of the liquid column height is determined by the pressure difference and the saturated liquid density.

a

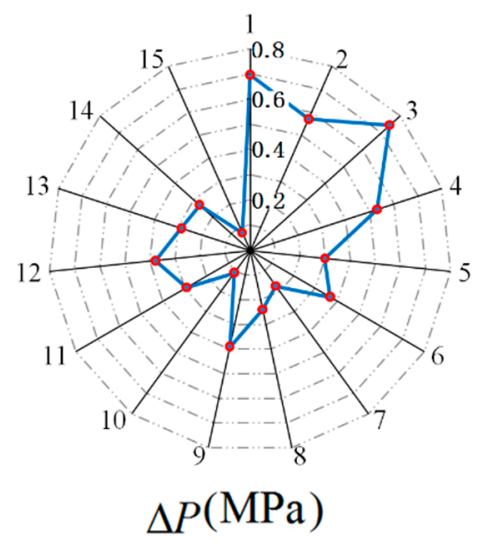

b

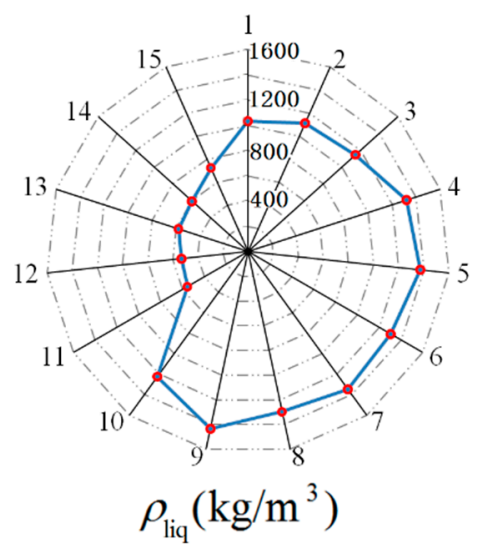

$\begin{array}{ll}5 & \text { R236ea } \\ 6 & \text { R236fa } \\ 7 & \text { R245ca } \\ 8 & \text { R245fa }\end{array}$

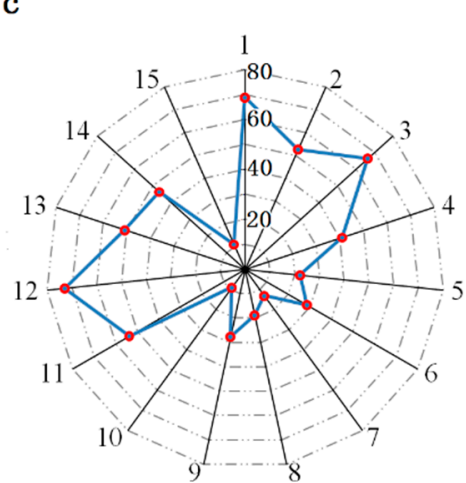

$H_{\text {liq }}(\mathrm{m})$

13 Trans-butene

14 Cis-butene

15 Cyclopentane

Figure 12. Parameters comparison for each fluid. (a. difference between saturated pressure at $62{ }^{\circ} \mathrm{C}$ and saturated pressure at $40^{\circ} \mathrm{C}$; b. saturated liquid density at $40^{\circ} \mathrm{C}$; c. fluid liquid column height).

It can be noted that the low liquid column height of R365mfc benefits from a low pressure difference while cyclopentane also benefits from high density. Therefore, except for good cycle 
performance, low saturated pressure (or difference between evaporating pressure and condensing pressure) and high density should also be determined as the principle for selecting fluid for GDOPC.

\section{Conclusions}

A theoretical method is used to study the cycle performance of GDOPC. Several fluids are investigated. The following conclusions can be drawn:

1. Kinetic energy loss in high vertical pipes and pump efficiency determine whether GDOPC gives better performance than ORC or not. When R245fa is selected as working fluid, specific energy in GDOPC (flow efficiency in high vertical pipes is specified as $80 \%$ ) is increased by $2.5 \%$ compared with that in ORC (pump efficiency is specified as $60 \%$ ) at each optimal condition.

2. The improvement degree of specific energy, as well as liquid column height, increases with rising evaporating temperature. High liquid column height means high construction difficulty and high system cost.

3. For GDOPC, R1234yf and R227ea give a good performance with specific energy of $4.84 \mathrm{~kJ} / \mathrm{kg}$ and $4.82 \mathrm{~kJ} / \mathrm{kg}$, respectively, while they need a high liquid column of as much as $76.55 \mathrm{~m}$ and $45.65 \mathrm{~m}$, respectively. Though R365mfc and cyclopentane don't have excellent cycle performance, they need low liquid column height of $9.04 \mathrm{~m}$ and $10.88 \mathrm{~m}$.

4. Fluid with low saturated pressure at specified temperature (or a difference between evaporating pressure and condensing pressure) and high saturated liquid density needs low liquid column height for GDOPC and has the potential to be used in practical application if the other performance indicators are not too bad.

Author Contributions: Conceptualization, L.P.; Data curation, W.S.; Formal analysis, W.S.; Methodology, L.P.

Acknowledgments: Project 51776215 supported by National Natural Science Foundation of China is gratefully acknowledged. This study is also supported by Beijing Natural Science Foundation $(3172008,3192042)$ and the Fundamental Research Funds for Beijing University of Civil Engineering and Architecture (X18143).

Conflicts of Interest: The authors declare no conflict of interest.

\section{Nomenclature}

$p$

$t$

$T$

S

h

$\rho$

$g$

in

$u$

E

Re

$\operatorname{Pr}$

$\mathrm{Nu}$

$d$

l

$\lambda$

$\zeta, \xi$

$\mathrm{Cp}$

M

$\dot{P}$

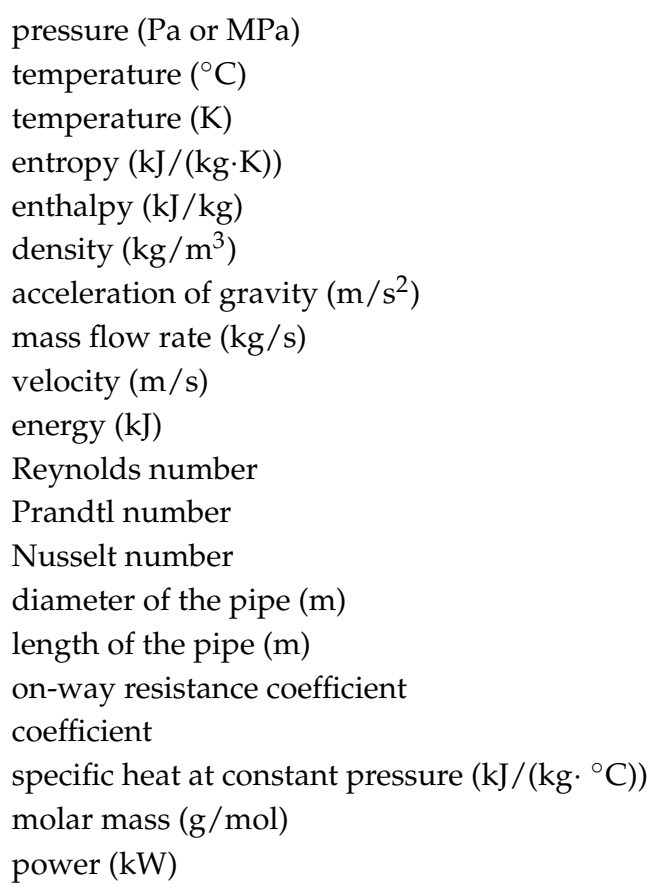




$\begin{array}{ll}Q & \text { heat capacity }(\mathrm{kW}) \\ G & \text { mss flow rate }(\mathrm{kg} / \mathrm{s}) \\ H & \text { column height }(\mathrm{m}) \\ \text { CHP } & \text { Combined heat and power } \\ \text { ODP } & \text { ozone depression potential } \\ \text { GWP } & \text { global warming potential } \\ \text { GDOPC } & \text { gravity driven organic power cycle } \\ \text { ORC } & \text { organic Rankine cycle } \\ 1,2,3,4,5,6,7,8 & \text { state points of ORC } \\ \text { Greek letters } & \\ \eta & \\ \text { Subscripts } & \text { efficiency } \\ \text { c } & \\ \text { b } & \text { critical } \\ \text { I } & \text { boiling } \\ \text { II } & \text { entrance of the fluid column unit } \\ \text { pp } & \text { exit of the fluid column unit } \\ \text { liq } & \text { pinch point } \\ \text { vap } & \text { liquid } \\ \text { isen } & \text { vapor } \\ \text { tur } & \text { isentropic } \\ \text { ther } & \text { turbine } \\ \text { evap } & \text { thermal } \\ \text { cond } & \text { evaporating } \\ 0 & \text { condensing } \\ \text { standard }\end{array}$

\section{References}

1. Tamamoto, T.; Furuhata, T.; Arai, N.; Mori, K. Design and testing of the organic Rankine cycle. Energy 2001, 26, 239-251. [CrossRef]

2. Desideri, U.; Bidini, G. Study of possible optimisation criteria for geothermal power plants. Energy Convers. Manag. 1997, 38, 1681-1691. [CrossRef]

3. Shen, A.; Liu, Q.; Duan, Y.; Yang, Z. Crossover equation of state for selected hydrocarbons (C4-C7). Chin. J. Chem. Eng. 2014, 22, 1291-1297. [CrossRef]

4. Desai, N.B.; Bandyopadhyay, S. Process integration of organic Rankine cycle. Energy 2009, 34, $1674-1686$. [CrossRef]

5. Liu, B.T.; Chien, K.H.; Wang, C.C. Effect of working fluids on organic Rankine cycle for waste heat recovery. Energy 2004, 29, 1207-1217. [CrossRef]

6. Tchanche, B.F.; Papadakis, G.; Lambrinos, G.; Frangoudakis, A. Fluid selection for a low-temperature solar organic Rankine cycle. Appl. Therm. Eng. 2009, 29, 2468-2476. [CrossRef]

7. Madhawa Hettiarachchi, H.D.; Golubovic, M.; Worek, W.M.; Ikegami, Y. Optimum design criteria for an Organic Rankine cycle using low-temperature geothermal heat sources. Energy 2007, 32, 1698-1706. [CrossRef]

8. Pan, L.; Wang, H. Improved analysis of Organic Rankine Cycle based on radial flow turbine. Appl. Therm. Eng. 2013, 61, 606-615. [CrossRef]

9. Pantano, F.; Capata, R. Expander selection for an on board ORC energy recovery system. Energy 2017, 141, 1084-1096. [CrossRef] 
10. Quoilin, S.; Lemort, V.; Lebrun, J. Experimental study and modeling of an Organic Rankine Cycle using scroll expander. Appl. Energy 2010, 87, 1260-1268. [CrossRef]

11. Lemort, V.; Quoilin, S.; Cuevas, C.; Lebrun, J. Testing and modeling a scroll expander integrated into an Organic Rankine Cycle. Appl. Therm. Eng. 2009, 29, 3094-3102. [CrossRef]

12. Qiu, K.; Thomas, M.; Douglas, M. Investigation of a scrool expander driven by compressed air and its potential applications to ORC. Appl. Therm. Eng. 2018, 135, 109-115. [CrossRef]

13. Mascuch, J.; Novotny, V.; Vodicka, V.; Spale, J.; Zeleny, Z. Experimental development of a kilowatt-scale biomass fired micro-CHP unit based on ORC with rotary vane expander. Renew. Energy 2018. [CrossRef]

14. Zhao, Y.K.; Lei, B.; Wu, Y.T.; Zhi, R.P.; Wang, W.; Guo, H.; Ma, C.F. Experimental study on the net efficiency of an Organic Rankine Cycle with single screw expander in different seasons. Energy 2018, 165, 769-775. [CrossRef]

15. Wang, X.D.; Zhao, L.; Wang, J.L.; Zhang, W.Z.; Zhao, X.Z.; Wu, W. Performance evaluation of a low-temperature solar Rankine cycle system utilizing R245fa. Sol. Energy 2010, 84, 353-364. [CrossRef]

16. Pan, L.; Wei, X.; Li, B.; Li, T. Experimental investigation on the $\mathrm{CO}_{2}$ transcritical power cycle. Energy 2016, 95, 247-254. [CrossRef]

17. Kang, S.H. Design and preliminary tests of ORC (organic Rankine cycle) with two-stage radial turbine. Energy 2016, 96, 142-154. [CrossRef]

18. Sauret, E.; Rowlands, A.S. Candidate radial-inflow turbines and high-density working fluids for geothermal power systems. Energy 2011, 36, 4460-4467. [CrossRef]

19. Pei, G.; Li, J.; Li, Y.Z.; Wang, D.Y.; Ji, J. Construction and dynamic test of a small-scall organic rankine cycle. Energy 2011, 36, 3215-3223. [CrossRef]

20. Zanellato, L.; Astolfi, M.; Serafino, A.; Rizzi, D.; Macchi, E. Field performance evaluation of geothermal ORC power plants with a focus on radial outflow turbines. Renew. Energy 2018. [CrossRef]

21. Feng, Y.Q.; Hung, T.C.; He, Y.L.; Wang, Q.; Chen, S.C. Experimental investigation of lubricant oil on a $3 \mathrm{~kW}$ organic Rankine cycle (ORC) using R123. Energy Convers. Manag. 2019, 182, 340-350. [CrossRef]

22. Pan, L.; Wang, H.; Shi, W. Regulation law of turbine and generator in organic Rankine cycle power generation experimental system. Trans. Tianjin Univ. 2014, 20, 237-242. [CrossRef]

23. Miller, E.W.; Hendricks, T.J.; Peterson, R.B. Modeling energy recovery using thermoelectric conversion integrated with an organic Rankine bottoming cycle. J. Electron. Mater. 2009, 38, 1206-1213. [CrossRef]

24. Srinivasan, K.K.; Mago, P.J.; Zdaniuk, G.J.; Chamra, L.M.; Midkiff, K.C. Improving the efficiency of the advanced injection low pilot ignited natural gas engine using organic rankine cycles. J. Energy Resour. Technol. 2008, 130, 022201-022207. [CrossRef]

25. Schenmaker, J.; Rey, J.F.Q.; Pirota, K.R. Buoyancy organic Rankine cycle. Renew. Energy 2011, 36, 999-1002. [CrossRef]

26. Boy-Marcotte, J.L.; Faillot, J.L.; Verneau, A. Apparatus Providing Electricity to Submarine Wellhead Equipments. French Patent FR9510946, 19 September 1995.

27. Li, J.; Pei, G.; Ji, J. A novel organic thermodynamic cycle on the use of gravity for pressurization. J. Eng. Thermophys. 2012, 33, 729-734.

28. Li, J.; Pei, G.; Li, Y.; Ji, J. Analysis of a novel gravity driven organic Rankine cycle for small-scale cogeneration applications. Appl. Energy 2013, 108, 34-44. [CrossRef]

29. Calm, J.M.; Hourahan, G.C. Refrigerant data summary update. HPAC Eng. 2007, 79, 50-64.

30. Györke, G.; Deiters, U.K.; Groniewsky, A.; Lassu, I.; Imre, A.R. Novel classification of pure working fluids for Organic Rankine Cycle. Energy 2018, 145, 288-300. [CrossRef]

31. Lemmon, E.W.; Huber, M.L.; McLinden, M.O. NIST Standard Reference Database 23. Reference Fluid Thermodynamic and Transport Properties (REFPROP), version 9.0; National Institute of Standards and Technology: Gaithersburg, MD, USA, 2010.

(C) 2019 by the authors. Licensee MDPI, Basel, Switzerland. This article is an open access article distributed under the terms and conditions of the Creative Commons Attribution (CC BY) license (http:/ / creativecommons.org/licenses/by/4.0/). 